\title{
Report of the Tobacco Policy Research Study Group on Access to Tobacco Products in the United States
}

Stanford University, Stanford, California D Altman

Americans for Nonsmokers' Rights, Berkeley, California J Carol

Utah Department of Health, Salt Lake City, Utah

C Chalkley

\section{SmokeFree}

Educational Services and Kidder Peabody, New York, New York

J Cherner

University of

Massachusetts,

Fitchburg,

Massachusetts

J DiFranza

Stanford University, Stanford, California

E Feighery

University of

Minnesota,

Minneapolis,

Minnesota

J Forster

Youth Representative S Gupta

North Bay Health

Resources Center,

Petaluma, California

J Records

UMD-Robert Wood Johnson Medica

School and St Peter's

Medical Center, New

Brunswick, New

Jersey

J Slade

Woodridge Police

Department,

Woodridge, Illinois

B Talbot

Stop Teenage

Addiction to Tobacco

and Baystate Medical

Center, Springfield,

Massachusetts

J Tye

Correspondence to: $\mathrm{Dr}$ David Altman, Center fo Research in Disease Prevention, Stanford Prevention, Stanford University School of Medicine, 1000 Welch Rd, Palo Alto,

David Altman, Julia Carol, Christine Chalkley, Joe Cherner, Joseph DiFranza, Ellen Feighery, Jean Forster, Sunil Gupta, John Records, John Slade, Bruce Talbot, Joe Tye

There are many factors that influence young people to start and to continue smoking. Interventions to reduce tobacco use can focus on either limiting the supply or decreasing the demand for tobacco. Clearly, interventions of both kinds are necessary. Efforts to reduce access should be complemented by comprehensive prevention curricula in schools, making schools smokefree zones, and the elimination of tobacco advertising and promotions, to name a few activities of high priority. Access to tobacco may be thought of as a system, comprised of the environment (tobacco outlets, distributors, companies) the agent (tobacco), and hosts (smokers, especially young people). Efforts to prevent tobacco use early in life should consider each component of this system; the eventual goal is a generation of young people who never start using tobacco.

This report summarises the body of research on access to tobacco by young people and outlines questions arising from this research.

\section{Background}

TOBACCO USE BY YOUNG PEOPLE

Nicotine is a powerful drug with addictive properties broadly analogous to those of the so called "hard drugs", cocaine and heroin. ${ }^{1}$. In 1990 , roughly $53 \%$ of high school seniors who smoked at least half a pack a day had made an unsuccessful attempt to stop smoking. Moreover, whereas only $5 \%$ who smoked daily thought that they would still be smoking five years later, about three quarters were still smoking seven to nine years later. ${ }^{2}$ Use of smokeless tobacco, especially among young males, has risen rapidly in recent years. An extensive review of smokeless tobacco ${ }^{3}$ found that between $40-60 \%$ of males had tried smokeless tobacco and 10-20\% of older teenagers reported recent use. ${ }^{4}$

Although alcohol consumption by teenagers generally receives more attention than their use of tobacco, tobacco is more often used by high school students on a daily basis. ${ }^{2}$ In the United States, the modal age of starting to use tobacco is between 11 and 15 with little initiation after high school graduation. ${ }^{2}$ The younger someone starts to use tobacco, the more likely they are to remain a user, to smoke heavily, to incur high costs for health care, and to die prematurely.
Although the National Institute on Drug Abuse survey found that daily smoking among high school seniors dropped from $29 \%$ in 1977 to $20 \%$ in 1981 , the 1990 rate of $19 \%$ shows the recent inability to affect adolescent tobacco use. ${ }^{2}$ This survey also found that in $199029 \%$ of seniors had smoked in the past month and $66 \%$ smoked occasionally. About one third of high school seniors do not believe that there is a great risk associated with use of tobacco. The prevalence of smoking is high among high school dropouts, transfer students, and truants.

EFFORTS OF THE TOBACCO INDUSTRY TO LURE MINORS

About 2.5 million smokers in the United States either stop smoking or die each year. This is the number that must be replaced to maintain existing sales levels. Clearly, a key marketing strategy of the tobacco industry is to create demand among young non-smokers. In 1988, the US tobacco industry spent $\$ 74$ million on free distribution of tobacco products. $^{5} \mathrm{~A}$ survey of Chicago students found that about half the elementary and high school students and $28 \%$ of college students had witnessed such free distribution to minors; $14 \%$ of elementary and high school students had personally received free tobacco samples. ${ }^{6}$ Also, $\$ 874$ million was spent on coupon (redemption) and "buy one, get one free" promotions, $\$ 190$ million on specialty item distribution (for instance, $T$ shirts, mugs), and $\$ 43$ million on direct mail. ${ }^{5}$

The tobacco industry also sponsors "It's the law", a low intensity retailer education programme in which retailers are encouraged to purchase signs indicating that sales to minors are prohibited. Public health professionals tend to view "It's the law" more as public relations than public or merchant education.

\section{ACCESS TO TOBACCO PRODUCTS BY YOUNG} PEOPLE

As of July 1991, 46 states and the District of Columbia had laws regulating tobacco sales to minors, but these laws are rarely enforced. An enforcement review found that five states had nominal restrictions (for example, laws ban- 
ning sales below a minimum age); 38 had age restrictions with penalties; four had moderate restrictions (basic restrictions plus warning signs, state issued retail licence, and a provision for licence suspension or revocation when sales to minors are made); but no state had comprehensive regulations (moderate regulations plus a ban on free distribution and coupons, use of licence fees for enforcement, vending machine restriction or ban, absence of a preemptive clause, and allowance for compliance checks/"stings" - where authorities monitor the selling rate to minors who are sent into shops to attempt to purchase tobacco - at the local level). ${ }^{?}$

In field trials, minors have successfully purchased tobacco from stores and vending machines $60-100 \%$ of the time. ${ }^{8-12}$ In the United States, annual illegal sales to minors are estimated at 947 million packs of cigarettes and 26 million containers of chewing tobacco. These sales total $\$ 1.45$ billion and generate more than $\$ 221$ million, 3\% of total industry profits. ${ }^{13}$ Studies in other countries show that the problem is similarly widespread. ${ }^{14,15}$

\section{SOURCES OF TOBACCO}

Minors obtain tobacco from various sources. A 1989 Chicago study (L Jason, personal communication, 17 July 1991) indicated that minors obtained $71 \%$ of their tobacco from over the counter sales. The outlets from which tobacco was purchased included petrol stations $(37 \%)$, food stores $(23 \%)$, and drug stores $(11 \%)$. A further $19 \%$ of tobacco was obtained from friends, $7 \%$ from parents, and $3 \%$ from vending machines. The minors interviewed were cost conscious; petrol stations were popular sales points because cigarettes there were typically less costly. The extent to which sales of single cigarettes contributes to the youth access problem is unknown, although there is evidence that single cigarettes are available in some communities in the United States. It should also be noted that in the United States store clerks are often minors. Minors who buy tobacco from clerks who are also minors can pose unique challenges to efforts to control tobacco access.

A national study sponsored by a vending machine trade group suggested an inverse relation between age and use of vending machines as a regular source of tobacco. ${ }^{16}$ Among those teenagers who reported purchasing tobacco products often or occasionally, $36 \%$ of 13 year olds and $14 \%$ of 17 year olds obtained them from a vending machine. Also, $56 \%$ reported that they used vending machines because they thought they would not be stopped; only $11 \%$ of teenagers reported they had ever been prevented from buying cigarettes from a vending machine. Vending machines represent an important means by which the youngest children obtain cigarettes.

RELATIONSHIP BETWEEN ACCESS AND USE

The most important questions that should be asked in research on access of the young to tobacco concern the relation between access and tobacco use. Two preliminary studies have directly examined this. ${ }^{17,18}$ In Woodridge, Illinois, researchers conducted a cross sectional survey of more than 600 seventh and eighth grade students about their smoking behaviour before and about two years after legislation was passed concerning retailer licensing, law enforcement, and possession of tobacco by young people. Experimental smoking (tried on at least one occasion) dropped from $46 \%$ at pretest to $23 \%$ at the two year post-test. Likewise, regular smoking dropped from $16 \%$ to $5 \% .^{17}$ In Leominster, Massachusetts, researchers surveyed over 500 12-19 year old students before and about two years after legislation was passed that encouraged law enforcement. The percentage of students identifying themselves as smokers dropped from $22.8 \%$ at pre-test to $15.8 \%$ at the two year post-test. In a complementary but supportive line of research, studies of school smoking policies indicated that making smoking inconvenient discouraged about $25 \%$ of would be smokers from starting. ${ }^{18}$

In summary, the Woodridge and Leominster studies provide strong support for the hypothesis that reducing tobacco access among young people can reduce their use of tobacco. Future studies should incorporate randomised designs, longitudinal as well as cross sectional samples, biochemical confirmation of self reported tobacco use, and long term follow up of tobacco use to assess whether these effects are maintained into the early adult years.

Zero tolerance for access of young people to tobacco products must become the community norm. Retailers, law enforcement officers, judges, health professionals, and others can have a major role in conveying a consistent, zero tolerance message to the community. A law that is not enforced is ineffectual. Unenforced laws imply that the subject and intent of the law is unimportant and need not be taken seriously. Conversely, activities necessary to limit access, such as enforcement, legislation, and publicity, raise awareness about the harm caused by tobacco, and pave the way for other efforts. If parents, government officials, and health professionals are to succeed in convincing children and teenagers to recognise that tobacco is detrimental to health, tobacco cannot be sold in vending machines as if it were candy and over the counter as if it were toothpaste.

\section{PUBLIC SUPPORT}

A 1989 population survey of 3654 persons aged 25-64 in the 10 Community Intervention Trial for Smoking Cessation (COMMIT) cities showed strong public support for regulating minors' access to tobacco. ${ }^{19}$ Across the 10 cities, $70 \%$ of respondents agreed that tobacco products should be as strictly controlled as alcohol products; $88 \%$ agreed that merchants who sell tobacco to minors should be fined; and $84 \%$ agreed that cigarette vending machines should be eliminated in places where teenagers gather. 
Interventions to reduce access to tobacco by young people

The primary response to tobacco use among young people has been the implementation of school based primary prevention programmes. Well designed school based programmes stressing life skills, increased self esteem and knowledge, resistance skills, and norms can be effective in delaying onset, in a subset of the targeted population. A few programmes have been shown to prevent tobacco use. The effects were, however, modest in the short term and uncertain in the long term. ${ }^{20-22}$ In isolation, school based programmes may lack the broad efficacy and long lasting impact necessary to alter the prevalence of tobacco use by the young.

After nearly three decades of work on education programmes, it is unlikely that a remarkably effective "magic bullet" programme will be discovered that makes enforcement of access laws unnecessary. Equally, limiting access alone may not be enough to reduce smoking prevalence among youth to acceptable levels. Thus implementation of mutually supportive interventions that target all factors which influence tobacco use are needed. Educational interventions are undermined when children are easily able to purchase tobacco. Thus, even if effective educational interventions were developed, their effectiveness would be reinforced and enhanced by strictly controlled access.

There is now a national consensus that more active steps must be taken to reduce access of young people to tobacco. ${ }^{8,12,17,18,23-28}$ Since the late 1980 s, communities around the country have shown a strong willingness to take action to limit such access. ${ }^{19}$ This has led to substantial progress in local laws and merchant practices. To date, various measures to reduce access of young people to tobacco have been implemented, including partial or total bans of vending machines, increasing enforcement of age of sale laws, merchant education programmes, posting warning signs at points of purchase, establishing a minimum age for clerks who sell tobacco, requiring single packs of cigarettes to be sold behind the counter, increasing penalties for sales to minors, and increasing the sales price through excise taxes. Little is known about which interventions are effective, their generalisability, whether or not the intervention's effect decays with time, or what can be done to enhance an intervention's effectiveness over time. Also, more information is required about the interactive and synergistic effects of using various interventions together.

\section{MERCHANT EDUCATION PROGRAMMES}

Most researchers agree that merchant education is necessary but not sufficient to reduce sales to minors. Interventions that encourage voluntary merchant compliance have achieved substantial but incomplete reductions in over the counter sales to minors, but these cannot sustain reductions without continued efforts.
For example, in Santa Clara County, California, a four month comprehensive educational intervention including direct merchant education, contact with executives of chains and franchises, mass media interventions, and community organisation reduced illegal sales from 74 to $39 \%$ among a sample of 412 stores. Six months after the intervention, sales had risen to $59 \%$. Vending machine sales to minors were $100 \%$ throughout the intervention..$^{8,9}$

\section{VENDING MACHINE POLICY OPTIONS}

Limiting minors' access to tobacco from vending machines has become a key priority for public health professionals because young minors so often utilise vending machines, and because merchants are reluctant to comply with restrictions on over the counter sales when minors can purchase from vending machines. In Minnesota, for example, more than 50 communities have adopted policies to restrict or prohibit cigarette vending machines. ${ }^{11,29}$ For various reasons, however, many jurisdictions have preferred to implement partial bans. These may prohibit machines from some locations or require the machines to be under supervision. Alternatively, some jurisdictions require vending machines to be equipped with locking devices or to require the buyer to purchase tokens from the retailer. These interventions are designed to allow the retailer to require proof of age from a potential buyer before unlocking the machine, or selling a token for the purchase of cigarettes.

Partial bans that permit vending machines in "adult" locations, such as bars, have not eliminated minors' access, as minors are often able to gain admission to such locations. Locking devices or token systems may reduce but not eliminate access by minors as the machines are difficult to supervise in a busy retail environment. A study in St Paul, Minnesota ${ }^{28}$ shows the difficulty of employing electronic locking devices. One year after St Paul enacted a law requiring vending machines to have locking devices, $30 \%$ of vending machines were not in compliance with the law and did not have locking devices installed. Ten per cent of the locations had converted to over the counter sales only, and $13 \%$ stopped selling tobacco altogether. The last group included those merchants who owned mechanical vending machines that could not be fitted with locking devices in retrospect or if they could, the cost was prohibitive. The overall ability of minors to purchase tobacco from vending machines was reduced from $86 \%$ before the law was enacted to $48 \%$ one year later. In locations that had installed locking devices on machines, a minor was still able to purchase tobacco $39 \%$ of the time. ${ }^{28}$ Thus enforcing locking device legislation is challenging: tedious compliance checks are necessary and many merchants ignore the law. Most advocates and researchers now believe that the only effective way to limit minors' access to vending machines is to ban the machines entirely. 
ENFORCEMENT OF LAWS TO DECREASE ACCESS TO YOUNG PEOPLE

Dr Louis Sullivan, head of the Department of Health and Human Services, directed the Office of the Inspector General (OIG) to study this issue. The 1990 OIG report consisted of case studies of active state and local enforcement efforts and the results of interviews with 1200 health experts, students, parents, and vendors from 18 states. $^{26}$ The report determined that although 44 states and the District of Columbia have laws prohibiting the sale of tobacco to minors, these laws are rarely enforced. Local leadership seemed to be the primary factor motivating active enforcement of tobacco laws.

As a result of this investigation, the "Model Sale of Tobacco Products to Minors Control Act ${ }^{25,30}$ was published, comprised of the primary components :

- Retailer licensing system

- A graduated set of penalties

- Investigation and enforcement conducted primarily in state agencies

- State administered civil penalties with use of local courts to assess fines

- Establishing 19 as legal age of purchase

- Banning vending machines.

In four diverse communities in Solano County, California, a combined comprehensive education and enforcement intervention reduced over the counter sales from $72 \%$ at baseline to $21 \%$ at two years post-test. Vending machine sales were $84 \%$ at baseline and $83 \%$ at post-test. ${ }^{10}$ One round of compliance checks resulted in 31 citations, 16 of which reached the courts, where all were dismissed or reduced. In Leominster, Massachusetts, 100 tobacco retailers ( 34 stores and 66 vending machines) were visited by underage minors on several occasions after active enforcement of access laws occurred. Although there was no preintervention measure of sales to minors, the sales rates after an educational and law enforcement intervention was implemented were assessed on three occasions: At 11 months after intervention, $19 \%$ of outlets sold to a 10 year old boy and a 13 year old girl; at 15 months two boys aged 11 and 12 were sold tobacco in $16 \%$ of the outlets they visited; at 19 months two 16 year old girls were sold tobacco in $65 \%$ of the outlets they visited. Also 17 of the 66 vending machines in the community were removed during this period. ${ }^{18}$ The experiences with enforcement in Woodridge, Illinois, are discussed in the next section.

\section{LAWS AND POLICIES}

In the United States merchants recognise that there are no actively enforced penalties attached to the sale of tobacco to young people. If retailer compliance is to be obtained, law enforcement agencies and the judicial system must be educated about the extent of the problem and motivated to respond. Public health officials rarely collaborate with local authorities regarding access to tobacco. More involvement and commitment from all agencies will need to occur to significantly increase compliance.

The consensus among health professionals is that administration of a tobacco vendor's licence is more appropriately done through the civil rather than the criminal courts. The preference for the civil route is based on several factors. Firstly, in most communities a civil offence would be handled more expediently and cost effectively than a criminal offence. Secondly, many health professionals are uncomfortable with the fact that clerks caught selling tobacco to minors will have a criminal record for life. Likewise, some judges in California communities have expressed concern about imposing a criminal penalty for what they consider a minor offence. ${ }^{11}$

There are more than a million tobacco outlets, encompassing a complex system of wholesalers and retailers. Wholesalers are able to earn commissions for routing efficiency, sales volume, and in at least one case, for political activity. It may not be feasible to adequately supervise these outlets without uniform licence requirements that are enforced. Because our understanding of the distribution network is limited, our ability to influence it is limited. As minors may simply patronise the remaining outlets that will sell them tobacco, it is critical to show that limiting the number of outlets accessible to the young has a measurable impact on the prevalence of smoking. To date, this has not been done. The large number of retail outlets for tobacco in the United States may be due to the fact that stocking tobacco builds customer traffic, is profitable, increases the likelihood that retailers will be given incentives to sell, and that wholesalers will be given incentives to have a large customer base.

There are examples of communities that have successfully passed access ordinances. In Woodridge, Illinois, a middle class suburb of Chicago (population 28000), for example, a law was passed that licenced tobacco vendors, suspended the licences of those found selling to minors, and banned possession by minors. This virtually eliminated sales to minors in a short period. ${ }^{17}$ Four of the five surrounding communities have adopted a tobacco licence law. In one of these (Bolingbrook) sales to minors dropped from $90 \%$ before the law and active enforcement was implemented to $23 \%$. Although strict enforcement of minor's access laws has been achieved in Woodridge, its overall impact is best considered in the light of the numerous communities around the country, both large and small, that have used the experiences of Woodridge to adopt stronger laws and effective enforcement. This diffusion effect has been substantial and rapid.

In some communities, merchants are most strongly influenced by seeing their tobacco customers walk across the street to their competitor's store than by a fine or threat of arrest. Many state laws are problematic, violations are criminal rather than civil, enforcement is limited to police departments, the judicial system is used for prosecution, and state laws may pre-empt local laws. Correcting 
these problems requires that public health professionals work in the political arena, in which many lack expertise or experience.

Finally, there has been considerable debate among public health professionals about the efficacy and desirability of laws that prohibit possession of tobacco by minors. In Woodridge, Illinois, minors' possession is illegal. Technically, this law does not criminalise minors who use tobacco because teenagers receive a citation written on a parking ticket with a maximum mail in fine of $\$ 25.00$. No arrest, police report, or juvenile contact record is made. Also, the apprehending officer does not confiscate the tobacco or inform the minors' parents.

In a survey of students in Woodridge, $93 \%$ were aware of the possession law, $72 \%$ thought it would help prevent them from smoking, and $55 \%$ thought it would prevent other students from smoking (B Talbot, personal communication). Other public health professionals argue that such possession laws divert attention away from merchants who sell tobacco to minors and tobacco industry tactics to recruit minors to use tobacco.

SIMILARITIES BETWEEN ALCOHOL AND TOBACCO Whereas there are important differences between alcohol and tobacco control philosophies, limiting the access of young people to tobacco and alcohol present similar challenges. Much research shows that laws and policies that restrict the availability of alcohol and increase the minimum age of purchase result in decreased alcohol consumption, alcohol related traffic accidents, and alcohol related health problems. ${ }^{31,32}$ For example, there is extensive evidence on the decreases in alcohol consumption among moderate and heavy drinkers and the resultant decreases in cirrhosis mortality brought about by prohibition. Data from the Centers for Disease Control show a 34\% decrease in the percentage of intoxicated teenage drivers involved in a fatal car crash. ${ }^{33}$ This reduction occurred coincident with increased public awareness of the hazards of drinking and driving, increased enforcement of existing laws against driving while drunk, enactment of more stringent laws, and the nationwide adoption of age 21 as the legal drinking age. Another historical precedent linking availability with consumption includes reduction in use of opium in England in the mid-1880s that was brought about by restricting its availability to pharmacies.

\section{Research priorities}

The five interrelated priority categories of research questions described next should direct more fine tuned research.

\section{ACCESS AND USE}

Two studies on the effects of limiting access on the initiation and prevalence of tobacco use by young people support just such a relation, ${ }^{17,18}$ but more research is needed. Ideally, studies should be randomised controlled trials, confirm self reports of tobacco use with biochemical markers (for example, cotinine), and track tobacco use longitudinally. Research is needed to assess whether reducing access among minors will simply delay the onset of tobacco use.

\section{EFFECTIVENESS OF EDUCATIONAL} INTERVENTIONS

Educational interventions directed at merchants and retailers, the community at large, young people, law enforcement agencies, and judges have been attempted. Overall, there are numerous important questions that remain to be investigated. Which are most effective at reducing youth access, under what conditions, and for whom? More specifically, the key research priority subareas include questions such as:

- Do point of purchase signs reduce selling to minors?

- Does heightened community awareness about access reduce access?

- Can knowledge of tobacco retail networks be used to make education more effective?

- What are the effects of the Tobacco Institute's "It's the Law" programme?

- What are effective point of sale messages?

- What educational approaches influence judges to support access laws?

- What is the impact on compliance of store visits versus education delivered via the media?

- What effects do manufacturers' incentive programmes for wholesalers and retailers have on youth access?

- What is the effective threshold of merchant compliance necessary to significantly reduce access?

- How can communities be encouraged to take actions such as collecting purchase data, reporting violations, writing letters, meeting with store managers?

- What are the most effective ways to reward retailers who consistently refuse to sell tobacco to minors?

- Are strategies to promote voluntary merchant compliance effective in the short term and/or long term?

- What are the best methods for involving young people in education?

\section{EFFECTIVENESS OF ACTIVE ENFORCEMENT} INTERVENTIONS

Enforcement of access laws through compliance checks is now recognised as a necessary component to any comprehensive intervention to reduce youth access to tobacco. Research questions arising include:

- What are the most effective types of law enforcement and what are their long term effects?

- What are the costs and benefits of routine compliance checks?

- What legal actions against the tobacco industry, distributors, or retailers are effective in reducing youth access to tobacco?

- What attitudes and beliefs do the public, 
vendors, and police hold toward enforcement of youth access laws?

- What are the obstacles to the widespread adoption of effective enforcement methods and how can these obstacles be overcome

- What is the optimal enforcement schedule?

- What are the compliance outcomes with different police, health department or others as enforcement agents?

\section{EFFECTIVENESS OF POLICIES AND LAWS}

In recent years, widespread attention has been paid to laws that address youth access to tobacco. A central issue here is the effect that state pre-emption of access laws has on local efforts to control access and what communities can do when pre-emption exists. Other key research priority subareas include questions about policies related to age of sale and purchase laws:

- What is the most effective and reasonable minimum age of purchase for tobacco?

- What are the effects on access of establishing a minimum age for people who sell tobacco?

- What are the effects of requiring tobacco to be sold from behind the counter only?

- What effect do single stick sales have on access and use?

- Does access vary based on type of tobacco purchased?

- What is the most effective method to control second party sales?

- What effects do restrictions on vending machine sales have on youth access?

- Do electronic remote control lockout devices or tokens installed on cigarette vending machines prevent minors from buying?

- To what extent do employees allow minors to use machines with inactivated control devices?

- Does licensure that includes suspension or revocation for sale to minors reduce access?

- What is the most effective period for licence suspension on first and repeated offences?

- Do laws that ban the purchase and possession of tobacco by minors affect access and use?

- At what age should possession be illegal?

- What sanctions, penalties, or treatment are appropriate for possession and use?

- What are the effects of holding different groups such as retailers, managers, owners, minors, and parents responsible for sales to minors?

- Is the enforcement of laws that treat tobacco in much the same manner as alcohol-suspension of vendor license for sales to minors, banning possession by minors - an effective means of reducing youth tobacco use?

\section{SOURCES OF TOBACCO}

Where minors obtain tobacco is central to our understanding of tobacco access issues. ${ }^{34}$ The key question in this category relates to proportion of contributors to minors' access made by various sources:

- Do the sources change as overall or source specific access is reduced?
We thank Ruth Corcoran of the American Cancer Society for overall guidance and Dearell Niemeyer of the California Department of Health Services for logistical and financial support.

1 US Department of Health and Human Services. Reducing the health consequences of smoking : 25 years of progress. $A$ report of the Surgeon General, 1989. Washington, DC Government Printing Office, 1989. (DHHS Publication No (CDC) 89-8411.)

2 Johnston LD, O'Malley PM, Bachman JG. National trends in drug use and related factors among American high school students and young adults, 1975-1990: Washington, DC: National Institute on Drug Abuse, 1991.

3 Boyd G et al. Use of smokeless tobacco among children and adolescents in the United States. Prev Med 1987; 16: 402-21.

4 Olds RS. Smokeless tobacco and teenagers: a time to act. American fournal of Health Promotion 1987; 2: 14-20.

5 Federal Trade Commission. Federal Trade Commission report to congress for 1988 pursuant to the Federal Cigarette Labeling and Advertising Act. Washington, DC: Federal Trade Commission, 1990

6 Davis RM, Jason LA. The distribution of free cigarette samples to minors. American fournal of Preventive Medicine 1988; 4: 21-6.

7 Choi WS, Novotny TE, Thimis AT. Restricting minors' access to tobacco: a review of state legislation, 1991.

8 Altman DG, Foster V, Rasenick-Douss L, Tye JB. Reducing the illegal sale of cigarettes to minors. $\mathcal{F} A M A$ $1989 ; 261: 80-3$.

9 Altman DG, Rasenick-Douss L, Foster V, Tye JB. Sustained effects of an educational program to reduce sales of cigarettes to minors. Am f Public Health 1991; 81: 891-3.

10 Feighery E, Altman DG, Shaffer G. The effects of combining education and enforcement to reduce tobacco sales to minors. $\mathcal{F} A M A 1991 ; 266$ : 3168-71.

11 Forster JL, Hourigan ME, McGovern P. Availability of cigarettes to underage youth in three communities. Prev Med 1992; $21: 320-8$

12 Stop Teenage Addiction to Tobacco (STAT). Tobacco and Youth Reporter. Contact: STAT, 121 Lyman Street, Suite 210, Springfield, Massachusetts, 01122, USA. (413/732-STAT.)

13 DiFranza JR, Tye JB. Who profits from tobacco sales to children? f $A M A$ 1990; 263 : 2784-7.

14 Minowa M, Satomi H, Japan: Sale of tobacco to minors. Lancet 1992; 339: 1163

15 Stanwick RS, Fish DG, Manfreda J, Gelskey D, Skuba A. Where Manitoba children obtain their cigarettes. $f$ Can Med Assoc 1987; 137: 405-8.

16 Response Research Inc. Findings for the Study of Teenage Cigarette Smoking and Purchase Behaviour (NB 6246), June/July 1989

17 Jason LA, Ji PY, Anes MD, Birkhead SH. Active enforcement of cigarette control laws in the prevention of cigarette sales to minors. $\mathcal{F} A M A$ 1991; 266: 3159-61.

18 DiFranza JR, Carlson RR, Caisse RE. Reducing youth access to tobacco. Tobacco Control 1992; 1: 57-8.

19 Cummings KM, Sciandra R, Pechacek TF, Corie D. Public attitudes regarding limits on public smoking and regulation of tobacco sales and advertising - 10 US communities, 1989. MMWR 1991; 40: 344-53.

20 Flay BR. Psychosocial approaches to smoking prevention: a review of findings. Health Psychology 1985; 4: 449-88.

21 Cleary PD, Hitchcock JL, Semmer N, Flinchbaugh LJ, Pinney JM. Adolescent smoking: Research and public policy. Millbank Quarterly 1988; 66: 137-71.

22 Glynn TJ. Essential elements of school-based smoking prevention programs. F Sch Health 1989; 59: 181-8.

23 DiFranza JR, Norwood BD, Garner DW, Tye JB. Legislative efforts to protect children from tobacco. FAMA 1987; 257: 3387-89.

24 Altman DG, Linzer JL, Kropp R, Descheemaeker N, Feighery E, Fortmann SP. Policy alternatives for reducing tobacco sales to minors: Results from a national survey of retail chain and franchise stores. $\mathcal{F}$ Public Health Policy 1992 (in press)

25 Sullivan LW: Statement of Louis W Sullivan, MD, Secretary of Health and Human Services, before the Committee on Finance, US Senate, May 24, 1990. (Presents "Model Sale of Tobacco Products to Minor (Presents "Model Sale of Tobacco Products to Minor Centers for Disease Control, Mail Stop K-50, 1600 Clifton Road, NE, Atlanta, Georgia 30333.

26 Office of the Inspector General. Youth access to cigarettes. May 1990; OEI-02-90-02310. Contact: Tracey Rennie, Room 38-100, 26 Federal Plaza, New York, New York $10278(212 / 264-1998)$.

27 Kirn TF. Laws ban minors' tobacco purchases, but enforcement is another matter. $\mathscr{f} A M A 1987 ; 257$ : 3323-4

28 DiFranza JR. Tobacco Access Law News (Feb, May, July, Nov 1990; Jan 1991)

29 Forster JL, Hourigan ME, Kelder S. Locking devices on cigarette vending machines: evaluation of a city ordinance. Am F Public Health 1992; 82: 1217-9.

30 US Centers for Disease Control. State laws restricting minors' access to tobacco. MMWR 1990; 39: 350-3.

31 Ashley MJ, Rankin JG. A public health approach to the prevention of alcohol-related health problems. Annu Rev Public Health 1988; 9: 233-71. 
32 Holder HD. Environmental restrictions and effective prevention policy. Advances in Substance Abuse 1987; suppl vention policy

33 US Centers for Disease Control. Premature mortality due to alcohol-related motor vehicle traffic fatalities - United to alcohol-related motor vehicle traffic fat
States, 1987. MMWR 1989; 37: 753-5.
34 Forster JL, Klepp-Inge K-I, Jeffery RW. Sources of cigarettes for tenth graders in two Minnesota cities. Health Education Research 1989; 4: 45-50 